\title{
MIDAZOLAM SYRUP AS A PREMEDICATION IN PAEDIATRIC PATIENTS- A RANDOMISED, DOUBLE- BLIND, PARALLEL GROUP, PLACEBO-CONTROLLED STUDY
}

\author{
Jaldeep BP1, Shilpa M. D2, Deepshikha CT ${ }^{3}$ \\ ${ }_{1}^{1}$ Assistant Professor, Department of Anaesthesia, Sir Takhtasinhji General Hospital and Government Medical College, Bhavnagar, \\ Gujarat, India. \\ ${ }^{2}$ Associate Professor, Department of Anaesthesia, Sir Takhtasinhji General Hospital and Government Medical College, Bhavnagar, \\ Gujarat, India. \\ ${ }^{3}$ Additional Professor, Department of Anaesthesia, Sir Takhtasinhji General Hospital and Government Medical College, Bhavnagar, \\ Gujarat, India.
}

\begin{abstract}
BACKGROUND
ABSTRACT

Premedication is expedient in reducing the psychological trauma from recalling the unpleasant pre-anaesthetic phases; hence, inducing a trouble-free anaesthesia.

Aim- This study was done to evaluate commercially available midazolam syrup $0.25 \mathrm{mg} / \mathrm{kg}$ as a premedication in children with regard to sedation, anxiolysis and parental separation score.
\end{abstract}

\section{MATERIALS AND METHODS}

After IRB approval and written informed consent from parents, this study was conducted in 100 children (ASA I and II), aged 1 to 6 years who were scheduled for various elective and emergency surgeries. Patients were randomly divided into two groups ( $\mathrm{n}=50$ each). Group A was control and Group B received midazolam syrup $0.25 \mathrm{mg} / \mathrm{kg} 45$ minutes before surgery.

\section{RESULTS}

The acceptance of drug was very good. All children in Group A (without premedication) were extremely anxious and crying or thrashing, while in Group B 98\% patients were calm and sleepy and separated happily from parents after 45 minutes. Midazolam did not impact the overall recovery time in children. None of the patients in either group developed any complication.

\section{CONCLUSION}

A dose of $0.25 \mathrm{mg} / \mathrm{kg}$ of commercially available midazolam syrup offers effective sedation and better emotional control facilitating better separation from parents.

\section{KEY WORDS}

Oral Midazolam, Children, Premedication.

HOW TO CITE THIS ARTICLE: Jaldeep BP, Shilpa M.D, Deepshikha CT. Midazolam syrup as a premedication in paediatric patients a randomised, double-blind, parallel group, placebo-controlled study. J. Evolution Med. Dent. Sci. 2018;7(28):3220-3223, DOI:

$10.14260 /$ jemds/2018/724

\section{BACKGROUND}

Surgery, in paediatric age group, can cause considerable distress and psychological consequences for both parents and children. Anxiety, in children undergoing surgery is characterised by subjective feelings of tension, apprehension, nervousness and worry. Children ( 1 - 5 years of age) are at the highest risk of developing anxiety than adults.[1] Postoperative maladaptive behaviour (e.g. enuresis, sleep disturbance), delayed recovery and other complications due to postoperative pain may result from preoperative anxiety if child is not reassured properly.[2] Before the induction of general anaesthesia, infants and preschool children frequently need medication to decrease their anxiety and to facilitate their separation from parents. Midazolam is most commonly used for this purpose.[3]

'Financial or Other Competing Interest': None.

Submission 30-05-2018, Peer Review 24-06-2018,

Acceptance 30-06-2018, Published 09-07-2018.

Corresponding Author:

Shilpa $M D$,

Associate Professor,

Dept. of Anaesthesiology,

Govt. Medical College,

Bhavnagar-364001, Gujarat, India.

E-mail:drshilpadoshi@yahoo.in

DOI: $10.14260 /$ jemds $/ 2018 / 724$

\section{(c) $(1) \ominus$}

Recent studies suggested that oral midazolam as preanaesthetic medication is as efficacious as intramuscular in paediatric patients. ${ }^{[4,5]}$ However, concerns have been raised regarding the potential of effective oral doses of midazolam to prolong recovery time.[4,6,7]

The use of premedication in anaesthesia is historical. Although, it is recognised that preoperative visit by anaesthesiologist provides a beneficial effect in terms of anxiolysis,[8] the use of drugs appear to be common. In 1998, Kain et al[9] reported that premedication with midazolam was more effective in reducing anxiety in preschool children than was parental presence at the time of induction of anaesthesia.

Before the development of commercially prepared syrup, oral midazolam formulation was prepared by mixing the intravenous midazolam product with variety of additives like apple, grape juice, paracetamol syrup to mask its bitter taste.[10,11] As the fat solubility of midazolam is $\mathrm{pH}$ dependant, non-standard oral formulations were prepared which have unpredictable absorption characteristic, bioavailability and stability.[12,13] Commercially prepared midazolam syrup is recently being introduced in India (July 2010). In literature there are limited studies ${ }^{[14,15]}$ on using this preparation as premedication in children and there is need for further research to evaluate its efficacy and safety profile as premedication in children. This prompted us to undertake 
this study with the purpose of examining the efficacy and safety of commercially prepared oral midazolam syrup as pre-anaesthetic medication in children.

\section{MATERIALS AND METHODS}

\section{Ethics and Study Design}

This prospective, randomised, double-blind, placebocontrolled, clinical study was conducted in 100 paediatric patients taken for convenience after the permission from Institutional Review Board (IRB) (IRB No. 184/2011), Govt. Medical College, Bhavnagar and obtaining written informed consent from the parents of children. The study was registered in Clinical Trial Registry of India (CTRI/2015/10/006234) and carried out as per guidelines of good clinical practice. Study was conducted in the Department of Anaesthesiology, Government Medical College and Sir Takhtasinhji General Hospital, Bhavnagar, Gujarat between $2010-12$.

\section{Recruitment Criteria}

Paediatric patients aged 1 to 6 years, of ASA physical status I and II, undergoing surgery with general or regional anaesthesia were evaluated and recruited in the study. Patients with age less than 1 year and more than 6 years, ASA physical status more than II, psychological disturbances, unstable haemodynamic and respiratory function, gastrointestinal problems, taking sedative and anticonvulsants for treatment and those whose parents did not give consent were excluded from the study.

Patients were randomised in 1: 1 ratio using computer generated random number sequence into two groups $(n=50)$. Sealed envelope technique was used as method of concealment. Group A patients received placebo (Rose flavoured Rasna syrup) $5 \mathrm{~mL}$, whereas Group B patients received midazolam syrup $0.25 \mathrm{mg} / \mathrm{kg}$ diluted in $5 \mathrm{~mL}$ distilled water, 45 mins before induction. Anaesthesiologist $\mathrm{X}$ had prepared the drug according to the group assigned. Anaesthesiologist Y (attending anaesthesiologist) was unaware about the content of the drug given and was also responsible for dispensing the drug to patients and recording observation.

\section{Study Procedure}

Patients were kept nil per oral for 4 hours before surgery. In pre-operative preparation room heart rate (HR), blood pressure (Systolic [SBP], Diastolic [DBP]), respiratory rate and peripheral arterial oxygen saturation $\left(\mathrm{SpO}_{2}\right)$ were recorded. Baseline sedation score, parental separation and anxiolysis score were recorded. After giving assigned treatment, anaesthesiologist Y recorded vital parameters, sedation score and parental separation and anxiolysis score immediately after giving drug and then at every five minutes interval till for forty-five minutes.

\section{Outcome Measures}

In the study HR, SBP, DBP, $\mathrm{SpO}_{2}$, Sedation Score $[1=$ Awake, active; 2= Awake, calm and quiet; $3=$ Drowsy- readily responds; 4= Asleep- responds slowly to gentle stimulation; $5=$ Asleep- not readily arousable $]$; Anxiolysis Score $[1=$ Vocal display of fear-apprehension; $2=$ Moderate expression of fear;
$3=$ Minimal expression of fear; $4=$ No fear $]$ and Parental Separation Scores [Unsuccessful $(1=$ Need for restrain; $2=$ Separate with crying); Successful ( $3=$ Separate without crying; 4= Happily separated)] were recorded just before giving the premedication and then after every 5 minutes up to 45 minutes. We recorded adverse drug reactions (ADRs) if any after giving the premedication in preoperative room, managed accordingly and reported to IRB.

\section{Statistical Analysis}

Overall, 100 patients were required to achieve $80 \%$ power at $5 \%$ significance level. Total number of patients required for each group were 50 patients. Quantitative data were expressed as mean and standard deviation, whereas descriptive statistics was used for categorical data. Comparison between two groups was done using GraphPad Prism 5 computerised software, unpaired t-test for quantitative data and chi-square test for qualitative data. $\mathrm{P}$ value $<0.05$ is considered statistically significant.

\section{RESULTS}

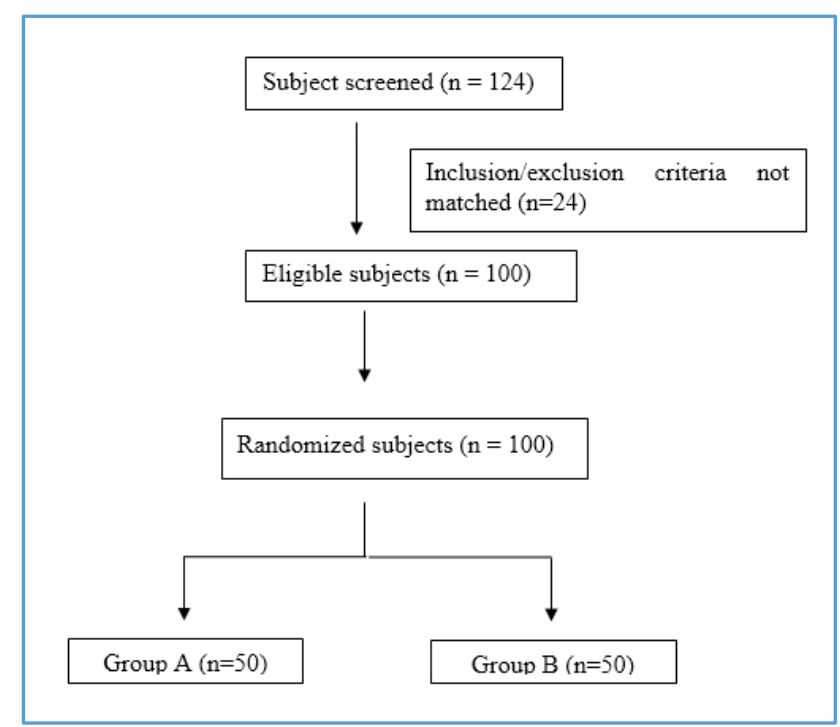

Figure 1. Study Flow Chart

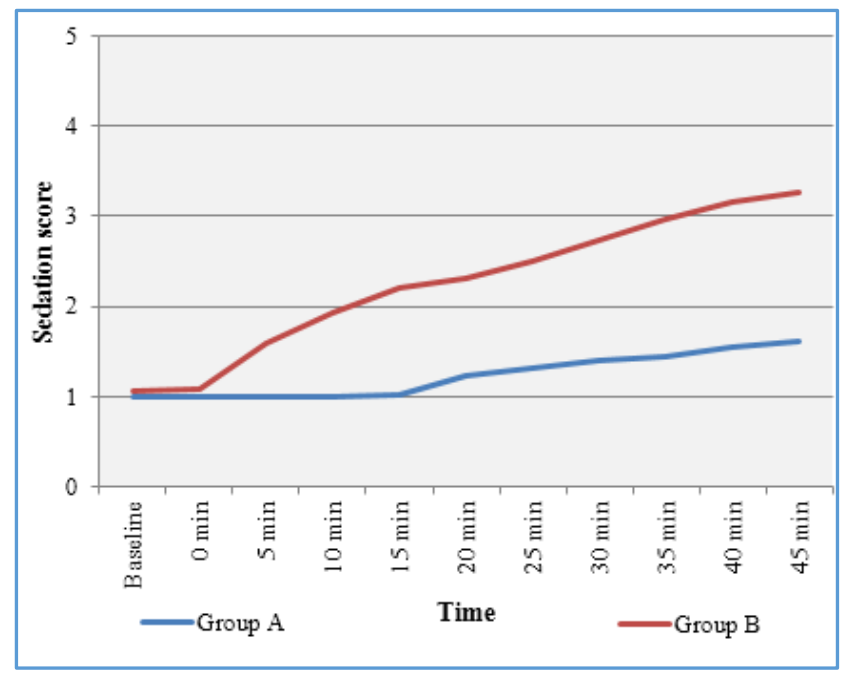

Figure 2. Changes in Sedation Score 


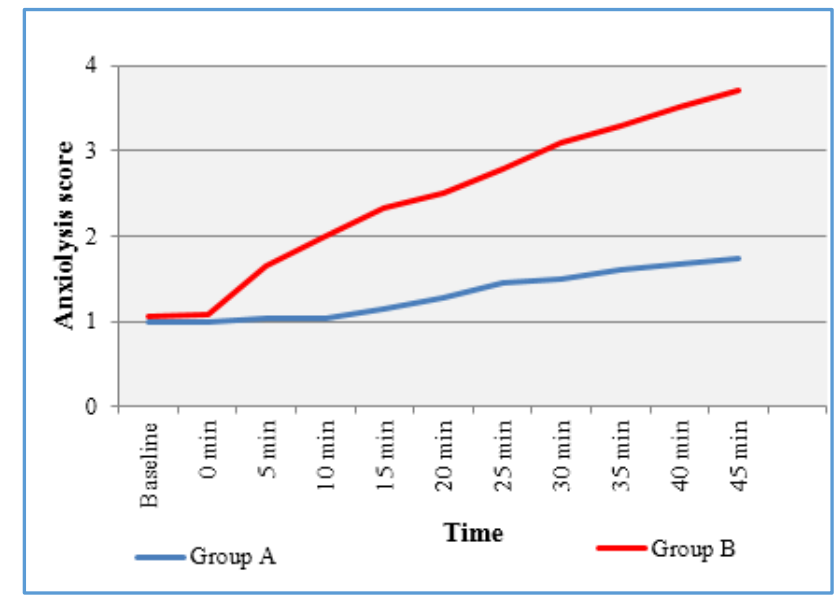

Figure 3. Changes in Anxiolysis Score

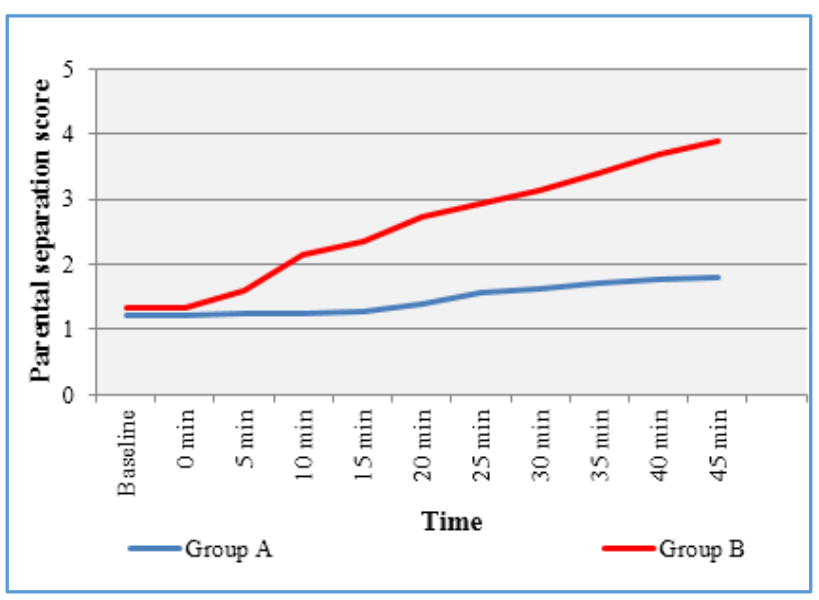

Figure 4. Changes in Parental Separation Score

\begin{tabular}{|c|c|c|c|}
\hline $\begin{array}{c}\text { Patient } \\
\text { Characteristics }\end{array}$ & $\begin{array}{c}\text { Group A } \\
\text { (n=50) }\end{array}$ & $\begin{array}{c}\text { Group B } \\
\text { (n=50) }\end{array}$ & P value \\
\hline $\begin{array}{c}\text { Age (years) } \\
\text { (Mean } \pm \text { SD) }\end{array}$ & $3.94 \pm 0.25$ & $3.85 \pm 0.24$ & 0.98 \\
\hline Gender (M/F) & $35 / 15$ & $33 / 17$ & 0.83 \\
\hline $\begin{array}{c}\text { Weight (kg) } \\
\text { (Mean } \pm \text { SD) }\end{array}$ & $12.34 \pm 0.75$ & $12.42 \pm 0.67$ & 0.94 \\
\hline ASA Physical Status (I/II) & $22 / 28$ & $24 / 26$ & 0.84 \\
\hline
\end{tabular}

Table 1. Patient Characteristics in Two Groups

The two groups were statistically similar in relation to age, gender, weight, ASA physical status (Table 1).

In Group A most of the patients were moderately apprehensive throughout the study period (Score $1\{28 \%\}, 2$ $\{72 \%\}$ ), while in Group B anxiolysis was achieved at 15 minutes and it continued to increase throughout the study (Score $3\{28 \%\}, 4\{72 \%\}$ ), (P value < 0.05 ) (Figure 2).

In Group B sedation was induced at 15 minutes and continued to sedation score of $3(78 \%)$ and $4(20 \%)$ at the end of 45 minutes (P value < 0.05) (Figure 3).

In Group A all patients were crying when separated from their parents (Score $1\{20 \%\}, 2\{80 \%\}$ ), while in Group B all patients were successfully separated from parents after 45 minutes of premedication (Score $3\{12 \%\}, 4\{88 \%\}$ ) which was statistically significant (P value $<0.05$ ) (Figure 4 ).

HR were uniformly decreasing in Group B as compared to baseline value, which was statistically significant $(P$ value $<0.0001$ ), but clinically insignificant. The SBP, DBP and $\mathrm{SpO}_{2}$ were comparable in both the groups ( $\mathrm{P}$ value $>0.05$ ). None of the patients in both the groups developed any complication.

\section{DISCUSSION}

Children, aged 1 to 6 years, are difficult to handle in preoperative period before surgery as they are extremely uncooperative, fearful, anxious, physically resistant and do not want to get separated from the parents. The major objectives of pre-anaesthetic medication in this age group are to alleviate anxiety and provide adequate degree of sedation for ease of parental separation. While going through the literature, many studies are available which used different sedative premedications in children.[16,17,18] However, there are reports of serious complications in the postoperative period while using some premedications.[6,7,19,20] The selection of most effective pre-medicant with optimum sedation, minimum complications and having high degree of parental satisfaction is difficult.

Midazolam is found to be an effective pre-anaesthetic medication for children, administered either orally,[21] rectally,[17,22] intramuscularly,[23] intranasally, [24] sublingually[25] and by jet injection. ${ }^{[26]}$ Of all the routes, oral is the most acceptable route in children because of its unique advantages.[19] This tempted us to use oral midazolam (Commercial formulation, recently introduced in Indian market in July 2010) as premedication in children.

Previous studies showed 30 minutes delay in achieving good sedation, hence midazolam was given 45 minutes prior to induction in present study.[27]

The results of the present study showed that with 0.25 $\mathrm{mg} / \mathrm{kg}$ of oral midazolam premedication, all the patients had good anxiolysis (score 3 and 4), successful separation from the parents (score 3 and 4) and were adequately sedated (score 3 and 4) at the end of monitoring period as compared to placebo group.

Sjoval et al[28] studied the effect of oral midazolam in a dose of $0.25 \mathrm{mg} / \mathrm{kg}$ and found it to be a satisfactory sedative agent. However, increased secretions were noted in their study. In another study, ${ }^{[18]}$ author used $0.4-0.6 \mathrm{mg} / \mathrm{kg}$ of oral midazolam and found only "fair" anxiolysis in children younger than 5 years of age. In contrast, oral midazolam 0.4 $0.6 \mathrm{mg} / \mathrm{kg}$ produced good anxiolysis in older children of more than 5 years of age. In another study[27] author used three doses of oral midazolam $0.25,0.5$ and $0.75 \mathrm{mg} / \mathrm{kg}$ and found them to be equally effective for sedation and anxiolysis without any circulatory, respiratory and long-term residual neurological defects in children. Results are comparable with the present study. There are other studies which used 1 $\mathrm{mg} / \mathrm{kg}{ }^{[17]}$ and $1.5 \mathrm{mg} / \mathrm{kg}^{[29]}$ of oral midazolam and found that the children were better sedated than with the standard dose $(0.5 \mathrm{mg} / \mathrm{kg})$ of midazolam.

In the study of McMillan et al,[19] excellent anxiolysis at the time of parental separation was found in $80 \%-90 \%$ of the children who received midazolam in a dose of $0.5,0.75$ and $1.0 \mathrm{mg} / \mathrm{kg}$. They concluded that all three doses of midazolam are equally effective and provided sedation and anxiolysis in children at the time of separation from parents, 30 minutes after administration of premedication. In another study, the author reported only $3 \%-7 \%$ incidence of excellent anxiolysis with $0.75 \mathrm{mg} / \mathrm{kg}$ of midazolam, while 0.25 and $0.5 \mathrm{mg} / \mathrm{kg}$ provided good anxiolysis in majority of patients, which is comparable to present study. 
In the present study, none of the patients developed any circulatory or respiratory adverse events.

\section{CONCLUSION}

To conclude midazolam syrup in a dose of $0.25 \mathrm{mg} / \mathrm{kg}$ can be an optimum dose for relieving anxiety, achieving good degree of sedation and successful separation from parents with stable haemodynamics without any adverse events.

\section{REFERENCES}

[1] McCann ME, Kain ZN. The management of preoperative anxiety in children: an update. Anaesthesia Analag 2001;93(1):98-105.

[2] Kain ZN, Mayes LC, Caldwell-Andrews AA, et al. Preoperative anxiety, postoperative pain and behavioral recovery in young children undergoing surgery. Pediatrics 2006;118(2):651-8.

[3] Pandit UA, Collier PJ. Oral transmucosal midazolam pre-anaesthetic medication for preschool children. Obstetric and Paediatric Anaesthesia 2000:191-5.

[4] Feld LH, Negus JB, White PF. Oral midazolam preanaesthetic medication in paediatric outpatients. Anesthesiology 1990;73(5):831-4.

[5] Nicolson SC, Betts EK, Jobes DR, et al. Comparison of oral and intramuscular pre-anaesthetic medication for paediatric inpatient surgery. Anaesthesiology 1989;71(1):8-10.

[6] Raybould D, Bradshaw EG. Premedication for day case surgery. A study of oral midazolam. Anaesthesiology 1987;42(6):591-5.

[7] Forrest P, Galletly DC, Yee P. Placebo controlled comparison of midazolam, triazolam and diazepam as oral premedicant for outpatient anaesthesia. Anaesthesia Intensive Care 1987;15(3):296-304.

[8] Egbert LD, Battit G, Turndrof $\mathrm{H}$, et al. The value of preoperative visit by an anaesthetist. A study of Doctor-Patient rapport. JAMA 1963;185(7):553-5.

[9] Kain ZN, Mayes LC, Wang SM, et al. Parental presence during induction of anaesthesia versus sedative premedication: Which intervention is more effective? Anaesthesiology 1998;89(5):1147-56.

[10] Kupferschmidt HH, Ha HR, Ziegler WH, et al. Interaction between grapefruit juice and midazolam in humans. Clinical Pharmacology 1995;58(1):20-8.

[11] Shrestha S, Shrestha BR. Oral administration of intravenous solution of midazolam mixed in syrup of paracetamol is an effective way of pre-medicating children undergoing surgery under general anaesthesia. Kathmandu Univ Med J (KUMJ) 2007;5(4):449-55.

[12] Walker SE, Grad HA, Haas DA, et al. Stability of parenteral midazolam in an oral formulation. Anaesth Prog 1997;44(1):17-22.

[13] Gregory DF, Koestner JA, Tobias JD. Stability of midazolam prepared for oral administration. South Med J 1993;86(7):771-2, 776.

[14] Brosius KK, Bannister CF. Midazolam premedication in children: a comparison of two oral dosage formulations on sedation score and plasma midazolam levels. Anaesthesia and Analgesia 2003;96(2):392-5.
[15] Cote CJ, Cohen IT, Suresh S, et al. Comparison of three doses of a commercially prepared oral midazolam syrup in children. Anaesthesia and Analgesia 2002;94(1):37-43.

[16] Bergendahl H, Lonngvist PA, Eksborg S. Clonidine in paediatric anaesthesia: review of the literature and comparison with benzodiazepines for premedication. Acta Anaesthesiol Scand 2006;50(2):135-43.

[17] Tanaka M, Sato M, Saito A, et al. Reevaluation of rectal ketamine premedication in children: comparison with rectal midazolam. Anaesthesiology 2000;93(5):121724.

[18] Saarnivaara L, Lindgren L, Klemola UM. Comparison of chloral hydrate and midazolam by mouth as premedicants in children undergoing otolaryngological surgery. Brit J Anaesth 1988;61(4):390-6.

[19] McMillan CO, Spahr-Schopfer IA, Sikich N, et al. Premedication of children with oral midazolam. Can J Anaesth 1992;39(6):545-50.

[20] Funk W, Jakob W, Riedl T, et al. Oral pre-anaesthetic medication for children: double blind, randomized study of combination of midazolam and ketamine versus midazolam or ketamine alone. Brit J Anaesth 2000;84(3):335-40.

[21] Cray SH, Dixon JL, Heard CM, et al. Oral midazolam premedication for paediatric day case patients. Paediatr Anaesth 1996;6(4):265-70.

[22] Andersen G, Pedersen NA, Johansson G, et al. Rectal midazolam as pre-medicant in children: a dose response study. Paediatr Anaesth 1994;4(6):365-70.

[23] Taylor MB, Vine PR, Hath DJ. Intramuscular midazolam premedication in small children. Anaesthesia 1986;41(1):21-6.

[24] Griffith N, Howell S, Mason DG. Intranasal midazolam for premedication of children undergoing day case anaesthesia: comparison of two delivery systems with assessment of intra-observer variability. Brit J Anaesth 1998;81(6):865-9.

[25] Geldner G, Hubmann M, Knoll R, et al. Comparison between three transmucosal routes of administration of midazolam in children. Paediatr Anaesth 1997;7(2):103-9.

[26] Greenberg RS, Maxwell LG, Zahurak M, et al. Preanaesthetic medication of children with midazolam using the biojector jet injector. Anaesthesiology 1995;83(2):264-9.

[27] Feld LH, Negus JB, White PF. Oral midazolam, optimal dose for paediatric premedication. Anaesthesiology 1989;71:A1054.

[28] Sjovall S, Kanto J, Iisalo E, et al. Midazolam versus atropine plus pethidine premedication in children. Anaesthesia 1984;39(3):224-8.

[29] Masue T, Shimonaka H, Fukao I, et al. Oral high-dose midazolam premedication for infants and children undergoing cardiovascular surgery. Paediatric Anaesthesia 2003;13(8):662-7. 